\title{
$\mathrm{MAO}$ 법을 이용한 산화피막처리에서 질산염 전해액성분 첨가에 따른 AZ31합금의 표면코팅 특성
}

\author{
조영희 ${ }^{1}$, 장경수 $^{1}$, 박세희 $^{1}$, 이호정 ${ }^{1}$, 이태행 $^{1^{*}}$
}

${ }^{1}$ 공주대학교 신소재공학부

\section{Effects of Nitrate Electrolyte as the MAO process for Ceramic Coating treatments of AZ31 alloy}

\author{
Young-Hee Cho ${ }^{1}$, Kyong-Soo Jang ${ }^{1}$, Sei-he Park ${ }^{1}$, Ho-jeong Lee ${ }^{1}$ \\ and Tae-Haeng Lee $^{1^{*}}$ \\ ${ }^{1}$ Dept. of Advanced Material Eng., Kongju National University
}

\begin{abstract}
요 약 $\mathrm{MAO}$ 법을 이용하여 전류밀도 $4 \mathrm{~A} / \mathrm{cm}^{2}$ 조건에서 3 종류의 전해액과 코팅시간에 따라 $\mathrm{AZ31}$ 마그네슘 합금을 산화 피막 처리하였다. 코팅시간이 길어짐에 따라 코팅층의 표면형상은 기공이 더욱 커지고, 표면에 균열이 발생하기도 하 였다. 또한 코팅시간이 길어짐에 따라 코팅층의 두께와 경도 $(\mathrm{HV})$ 값은 증가하였다. $\mathrm{AZ31}$ 합금의 코팅층 상들은 $\mathrm{MgO}$, $\mathrm{Mg}_{2} \mathrm{SiO}_{4}$ 그리고 $\mathrm{MgAl}_{2} \mathrm{O}_{4}$ 산화물로 이루어졌다. 산화코팅된 $\mathrm{AZ31}$ 합금을 $5 \% \mathrm{NaCl}$ 용액에서 168 시간동안 염수분무실 험결과 우수한 내식성을 나타냈다.
\end{abstract}

\begin{abstract}
AZ31 Mg alloy were coated by Macro Arc Oxidation(MAO) with 3 types of electrolyte and various coating times at $4 \mathrm{~A} / \mathrm{cm}^{2}$. The Surface morphology of coatings became lager pores and surface crack initiated as the coating time increased. The thickness and micro-hardness of coatings increased as the coating time increased. also. The phase of coatings on AZ31 alloy consisted of $\mathrm{MgO}, \mathrm{Mg}_{2} \mathrm{SiO}_{4}$ and $\mathrm{MgAl}_{2} \mathrm{O}_{4}$ oxides. The salt spray corrosion resistance of coated AZ31 alloys revealed excellent corrosion resistance in $5 \% \mathrm{NaCl}$ solution for $168 \mathrm{hr}$.
\end{abstract}

Key Word : Micro Arc Oxidation; Magnesium Alloy; AZ31; Ceramic Coating; Electrolyte

\section{1. 서론}

마그네슘은 비중이 1.74 인 경량금속으로 비강도, 비탄 성율이 우수하고 진동 흡수성과 전자파차폐성이 뛰어나 자동차, 항공부품과 같은 수송용 재료에서부터 전기, 전 자제품의 케이스 및 각종 부품으로 응용범위가 넓어지고 있으며, 최근에는 자동차부품의 경량화 추세에 따라 Air conditioner, Wheel, Bumper 등을 마그네슘으로 변경하는 연구가 활발히 이루어지고 있다. 그렇지만 마그네슘의 여 러 가지 양호한 기계적 특성에도 불구하고 내식성 및 가
공성이 떨어져 활용도가 제한되어 왔으며, 최근에는 가공 기술의 발달과 함께 내식성 향상을 위해 소재의 표면에 Anodizing 및 크로메이트 처리 등의 표면처리 기술을 이 용하여 이상의 단점을 보완하여 왔다.[1] 그럼에도 불구 하고 현재의 마그네슘 표면처리 방법은 표면 경화층 내 부 기공들과 낮은 표면 경도값으로 인해 내식성 및 내마 모성을 저하시키고, 표면 처리에 사용하는 강산 및 6 가 크롬에 의한 유해성 등으로 많은 환경문제를 유발하는 단점을 가지게 되었다.[2]

따라서 최근에 이러한 문제점을 개선하기 위하여

\footnotetext{
이 논문은 공주대학교 학술연구비의 지원에 의해 수행되었음.

${ }^{*}$ Corresponding Author : Tae-Haeng Lee

Tel: +82-10-8795-1094 email: thlee57@kongju.ac.kr
}

접수일 12 년 09 월 20 일 수정일 12 년 10 월 08 일 게재확정일 12 년 10 월 11일 
MAO(Micro-Arc Oxidation)법을 이용하여 다양하게 연구 되고 있으며, 세라믹코팅처리 공정 및 코팅층의 특성분석 에 대한 연구가 활발히 진행되고 있다.[3]

$\mathrm{MAO}$ 공정은 전해조에서 고전압을 걸어 모재 표면에 전기화학적인 산화반응을 유도하여 치밀한 세라믹 코팅 층을 모재 표면에 생성시키는 방법으로 기존 표면처리 기술보다 치밀한 코팅층을 얻을 수 있는 장점이 있 다.[3,4] 근래에는 국내·외서 활발한 연구로 자동차용 피 스톤부품과 임플란트와 같은 생체재료, 각종 전자기기 케 이스 등의 시제품이 발표 되고 있으나,[5] 아직까지도 명 확한 표준과 생산시스템이 정립되지 않고 여러 가지 안 이 제안되고 있다.

본 연구는 기존에 사용되고 있는 알칼리 전해액 중에 서 질산염을 첨가하여 $\mathrm{MAO}$ 반응 특성이 양호하고, 내식 성 및 외관이 깨끗한 세라믹 산화피막층을 얻는데 목적 이 있으며,[3,7] 특히 현재 산업체에서 많이 생산되고 있 는 아노다이징(Anodizing)용 DC 전원장치를 응용, 보안 설계하여 주파수 제어가 가능하면서 $\mathrm{MAO}$ 실험에 적합 한 Pulsed $\mathrm{AC}$ 전원장치를 제작하여 전압에 따른 시간 조 건별 산화피막층의 변화와 특성을 검사하여 새롭게 응용 할 수 있는 방안을 찾아보았다. 또한 일정한 전류밀도에 서 알카리 전해액과 질산염이 첨가된 전해액의 시편을 제조한 후 기계적 특성 및 내식성 실험을 통해 산화피막 특성에 대해 연구하였다.

\section{2. 실험방법}

본 연구를 위해 상용 $\mathrm{AZ3} 1$ 합금 $(3.85 \% \mathrm{Al}, 1.02 \% \mathrm{Zn}$, $0.55 \% \mathrm{Mn}, 0.2 \% \mathrm{Fe}$ and $\mathrm{Mg}$ balance) 판재를 준비하여 $40 \times 50 \times 2 \mathrm{~mm}$ 로 각각 절단하고, 전처리과정으로는 알코올 중에 5 분 동안 초음파 세척 한 후 열풍으로 건조하였다. 직경 $2.4 \mathrm{~mm}$, 길이 $15 \mathrm{~mm}$ 의 Pure Al Wire를 이용, 시편의 상부를 고정하여 반응용 $\mathrm{Bath}$ 의 중앙에 고정시키고 SUS316 으로 음극 전극을 연결하였다. 전해액은 $\mathrm{KOH}(3 \mathrm{~g} / \mathrm{L}), \mathrm{KF}(2 \mathrm{~g} / \mathrm{L}), \mathrm{Na}_{2} \mathrm{SiO}_{3}(5 \mathrm{~g} / \mathrm{L})$ 와 증류수로 구성되 어 있으며, 첨가한 질산염 성분으로 $\mathrm{NaNO}_{3}(0.5 \mathrm{~g} / \mathrm{L})$ 과 $\mathrm{NaNO}_{2}(0.5 \mathrm{~g} / \mathrm{L})$ 를 사용하였다. ${ }^{[4,12,13]}$ 실험에 사용한 MAO 장치[그림 1]는 크게 전원발생장치, 전해조와 냉각장치로 구성되어 있으며 전해액은 냉각장치를 이용하여 $20^{\circ} \mathrm{C}$ 이 하로 제어시켜 실험을 실시하였다. Pulsed $\mathrm{AC}$ 전원을 $400 \mathrm{Voltage}(100 \mathrm{~Hz})$ 로 인가하여 $4 \mathrm{~A} / \mathrm{cm}^{2}$ 전류밀도를 유지 하면서 $5 \mathrm{~min} .10 \mathrm{~min}, 15 \mathrm{~min}$ 동안 반응하여 산화피막층 형성을 관찰하였다.

$\mathrm{AZ31}$ 마그네슘 합금과 산화피막층 단면과 표면 형상
은 주사전자현미경(FE-SEM)으로 관찰하였고, 산화피막 층의 결정구조를 조사하기 위해 $\mathrm{X}$-선 회절분석기 (XRD;Rigaku D/MAX 2500H)로 상분석을 하였다.

미소비커스경도기(Matsuzawa;MMT7)를 이용하여 25gf 의 하중으로 산화피막층 단면의 경도를 측정하였으며, 산 화피막층의 부식특성을 평가를 위해 $5 \% \mathrm{NaCl}, 168$ 시간동 안 $35^{\circ} \mathrm{C}$ 의 분위기에서 염수분무시험을 실시하였다.

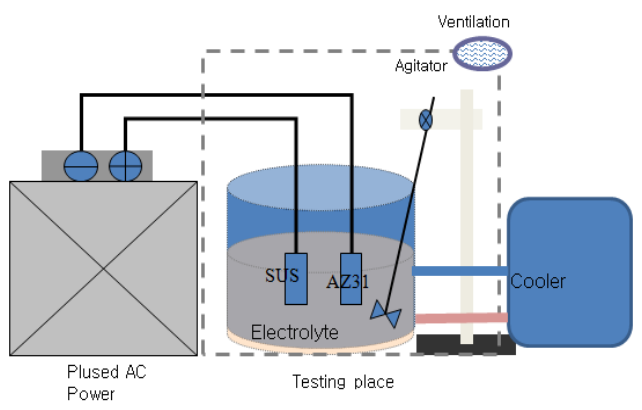

[그림 1] MAO 장비의 개략도

[Fig. 1] Schematic diagram of the MAO Equipment.

\section{3. 결과 및 고찰}

그림2는 전해액성분이 $\mathrm{KOH}(3 \mathrm{~g} / \mathrm{L}), \mathrm{KF}(2 \mathrm{~g} / \mathrm{L}), \mathrm{Na}_{2} \mathrm{SiO}_{3}$ $(5 \mathrm{~g} / \mathrm{L})$ 와 증류수로 구성되어 있는 혼합 전해액과 이에 질 산염 성분인 $\mathrm{NaNO}_{3}(0.5 \mathrm{~g} / \mathrm{L})$ 과 $\mathrm{NaNO}_{2}(0.5 \mathrm{~g} / \mathrm{L})$ 를 첨가한 후 각각 $5 \mathrm{~min}, 10 \mathrm{~min}, 15 \mathrm{~min}$ 동안 $4 \mathrm{~A} / \mathrm{cm}^{2}$ 의 전류밀도로 반응 했을 때의 산화피막 표면의 형상을 보여주고 있다.

산화피막 표면은 미세한 기공에서부터 분화구 모양의 매우 큰 기공까지 다양하게 분포하고 있으며 반응시간이 증가하면서 기공이 커지고, 크랙 발생량이 증가하는 것을 볼 수 있다. 특히, Pancake 모양의 기공은 MAO반응을 설 명하는 중요한 특징으로 자주 인용되고 있다.[3,6] $\mathrm{NaNO}_{3}(0.5 \mathrm{~g} / \mathrm{L})$ 과 $\mathrm{NaNO}_{2}(0.5 \mathrm{~g} / \mathrm{L})$ 를 첨가한 전해액에서 보다 활발하게 반응이 발생하는 것을 확인할 수 있었으 며, 그림2의 산화피막 표면에서의 분화구 모양의 큰 기공 이 더 많은 것으로 확인 할 수 있다. 이는 최근 보고된 연 구에서 질산염이 첨가된 전해액에서 이와 같은 Discharge channel이 더 증가되는 것으로 발표된 것과도 일치한 다.[7] 그림3은 산화피막층의 단면을 주사전자현미경 $(\mathrm{Fe}-\mathrm{SEM})$ 사진을 이용하여 측정한 그림으로 반응시간이 증가함에 따라 산화피막층의 단면두께는 증가하고 있으 며 전해액 성분에 따라 두께 변화는 크지 않은 것으로 나 타났다. 

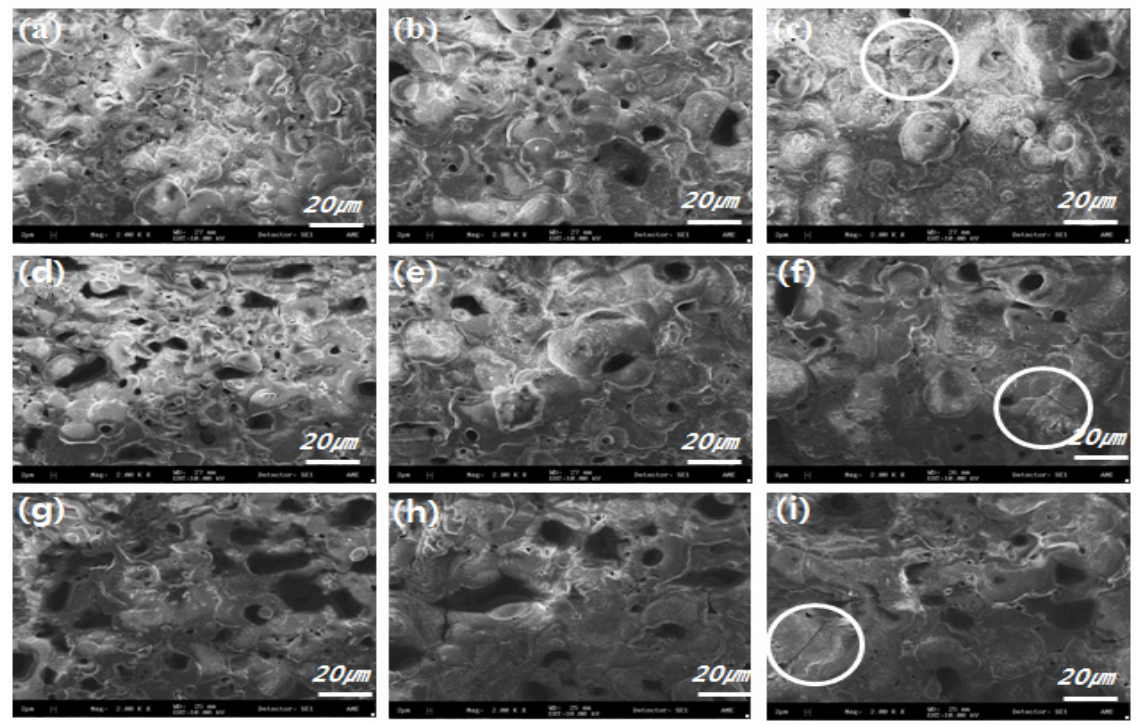

[그림 2] 알카리 전해액(a:5min, b:10min, $\mathrm{c}: 15 \mathrm{~min})$ 과 질산염 첨가 전해액(d:5min, e:10min, $\mathrm{f}: 15 \mathrm{~min})$, 아질산염첨가 전해액의 반응시간 $(\mathrm{g}: 5 \mathrm{~min}, \mathrm{~h}: 10 \mathrm{~min}, \mathrm{i}: 15 \mathrm{~min})$ 에 의한 MAO처 리한 표면형상

[Fig. 2] Surface morphologies of $\mathrm{AZ31} \mathrm{Mg}$ alloy after $\mathrm{MAO}$ treated in $\mathrm{KOH}(3 \mathrm{~g} / \mathrm{L})+$ $\mathrm{KF}(2 \mathrm{~g} / \mathrm{L})+\mathrm{Na}_{2} \mathrm{SiO}_{3}(5 \mathrm{~g} / \mathrm{L})$ electrolytes at (a) $5 \mathrm{~min}$, (b) $10 \mathrm{~min}$, (c) $15 \mathrm{~min}$ and $\mathrm{NaNO}_{3}(0.5 \mathrm{~g} / \mathrm{L})$ contained electrolytes at (d) $5 \mathrm{~min}$, (e) $10 \mathrm{~min}$, (f) $15 \mathrm{~min}$ and $\mathrm{NaNO}_{2}(0.5 \mathrm{~g} / \mathrm{L})$ contained electrolytes at (g) $5 \mathrm{~min}$, (h) $10 \mathrm{~min}$, (i) $15 \mathrm{~min}$

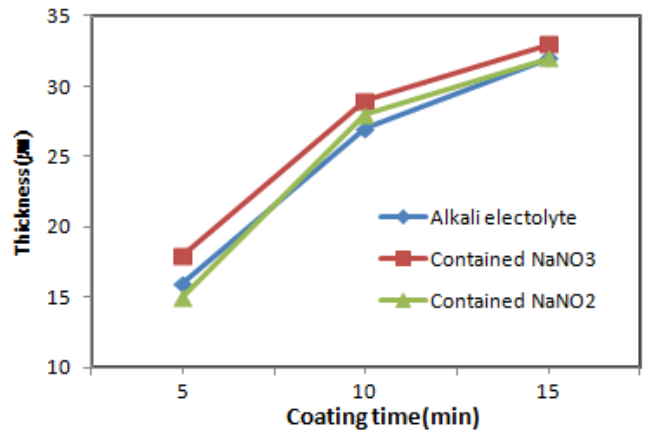

[그림 3] 반응시간에 따른 산화피막층 두께변화

[Fig. 3] Variations of thickness of coatings with increasing coating time(min)

이는 그림 4의 산화피막 단면 사진을 통해 보다 자세 하게 확인하였다.

질산염이 첨가된 전해액과 산화피막층 형성에 대한 두 께 변화는 크지 않은 것으로 판단된다.

산화 피막층 단면에서 외각층으로 갈수록 기공과 크랙 등에 의한 불규칙한 면이 모두에서 관찰되었다.

이와 같은 기공은 산화피막층의 내구성, 경도 등 여러 가지 특성에 중요한 인자로 자리잡고 있다.[8]
그림 5는 $\mathrm{MAO}$ 처리후, 마그네슘 표면으로 부터 $10 \mu \mathrm{m}$ 인 지점의 비커스경도값을 측정한 그림이다. 최외각층은 기공 및 크랙 등에 의해 영향을 받기 쉽기 때문에 피막층 의 내부의 조밀층에서 경도값을 비교한 것으로 질산염이 첨가된 전해액에서 반응시간에 관계없이 다소 높게 나타 났다. 특히, $\mathrm{MAO}$ 를 통해 15 분 동안 반응 했을때에 $\mathrm{NaNO}_{3}(0.5 \mathrm{~g} / \mathrm{L})$ 첨가된 전해액은 $207 \mathrm{Hv}, \mathrm{NaNO}_{2}(0.5 \mathrm{~g} / \mathrm{L})$ 첨가된 전해액은 $201 \mathrm{Hv}$, 질산염이 첨가되지 않은 알카리 전해액은 $180 \mathrm{Hv}$ 의 비커스 경도값을 나타냈다. 이는 전해 액 내에서 질산염 성분이 단단한 특성을 가지는 $\mathrm{Mg}$ 산화 물의 형성에 도움을 주는 것으로 판단되며, 마그네슘의 표면경도 향상은 내식성과 내마모성 향상에 영향을 미치 고 있다.

전해액 중의 질산염과 알카리 성분에 따라 산화피막층 을 구성하는 결정구조를 $\mathrm{XRD}$ 을 통해서 확인하였으며, 각각의 전해액에 따른 결정구조와 성분을 그림6과 같이 보여주고 있다. 알카리 전해액에서 $400 \mathrm{~V}(100 \mathrm{~Hz}), 4 \mathrm{~A} / \mathrm{cm}^{2}$ 전압을 인가하여 (a)5min, (b) $15 \mathrm{~min}$ 동안 반응 했을 때와 $\mathrm{NaNO}_{3}(0.5 \mathrm{~g} / \mathrm{L})$ 첨가된 전해액에 (c) $15 \mathrm{~min}$ 동안, $\mathrm{NaNO}_{2}(0.5 \mathrm{~g} / \mathrm{L})$ 첨가된 전해액은 (d) $15 \mathrm{~min}$ 동안 반응했을 때 산화피막의 결정구조를 보면 주로 $\mathrm{Mg}, \mathrm{MgO}, \mathrm{Mg}_{2} \mathrm{SiO}_{4}, \mathrm{MgAl}_{2} \mathrm{O}_{4}$ 로 구성되어있는 것으로 확인할 수 있다. 

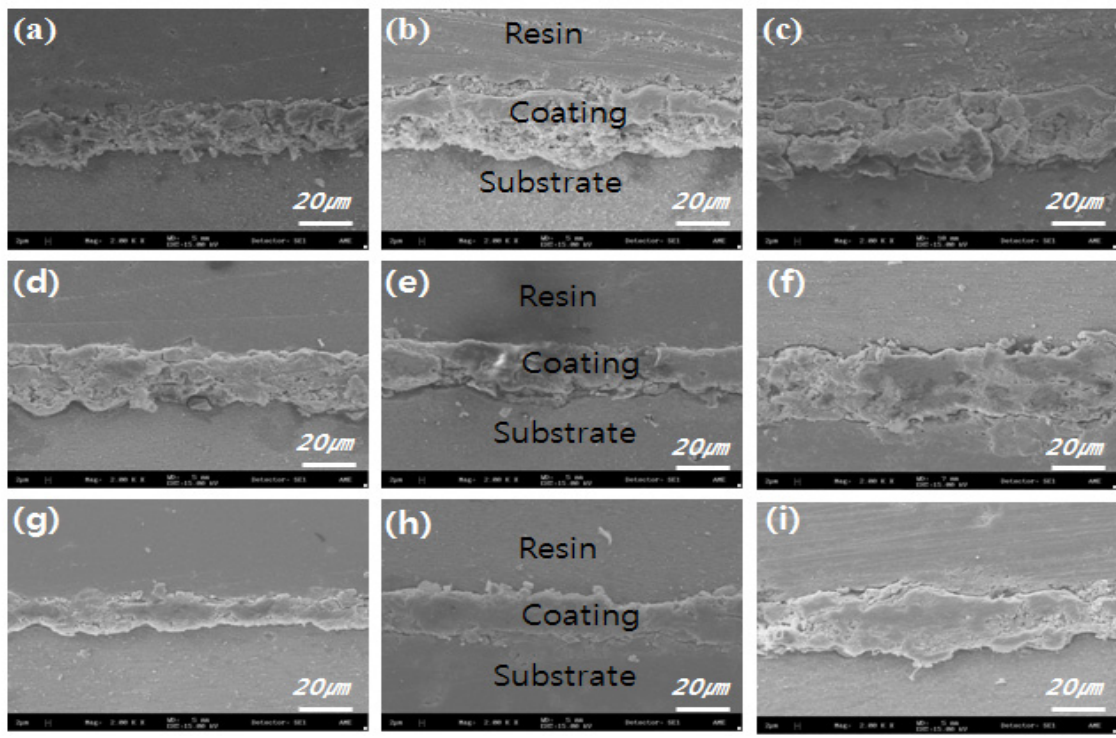

[그림 4] 알카리 전해액(a:5min, b:10min, c: $15 \mathrm{~min})$ 과 질산염 첨가 전해액(d:5min, e:10min, $\mathrm{f}: 15 \mathrm{~min})$, 아질산염첨가 전해액의 반응시간 $(\mathrm{g}: 5 \mathrm{~min}, \mathrm{~h}: 10 \mathrm{~min}, \mathrm{i}: 15 \mathrm{~min})$ 에 의한 MAO 처리한 단면조직

[Fig. 4] Cross sections of $\mathrm{AZ} 31 \mathrm{Mg}$ alloy after $\mathrm{MAO}$ treated in $\mathrm{KOH}(3 \mathrm{~g} / \mathrm{L})+\mathrm{KF}(2 \mathrm{~g} / \mathrm{L})+$ $\mathrm{Na}_{2} \mathrm{SiO}_{3}(5 \mathrm{~g} / \mathrm{L})$ electrolytes at (a)5min, (b) $10 \mathrm{~min}$, (c) $15 \mathrm{~min}$ and $\mathrm{NaNO}_{3}(0.5 \mathrm{~g} / \mathrm{L})$ contained electrolytes at (d) $5 \mathrm{~min}$, (e) $10 \mathrm{~min}$, (f) $15 \mathrm{~min}$ and $\mathrm{NaNO}_{2}(0.5 \mathrm{~g} / \mathrm{L})$ contained electrolytes at (g) $5 \mathrm{~min},(\mathrm{~h}) 10 \mathrm{~min}$, (i) $15 \mathrm{~min}$

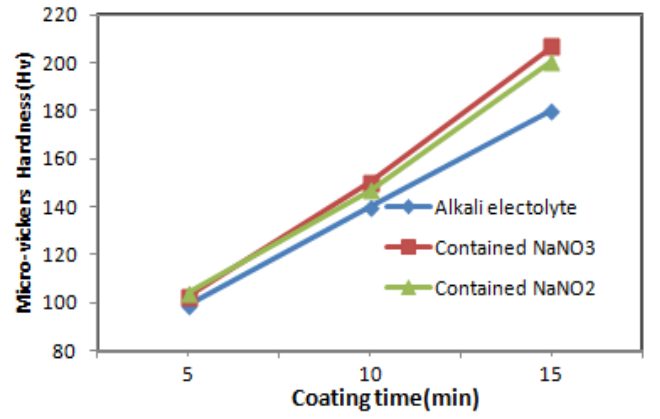

[그림 5] 반응시간에 따른 산화피막층의 경도변화

[Fig. 5] Variations of microhardness of coatings with increasing coating time (min)

모재인 $\mathrm{Mg}$ 이외에 마그네슘합금의 $\mathrm{MAO}$ 반응에서 주 로 생성되는 세라믹성분이 나타났으며,[9] $\mathrm{MgAl}_{2} \mathrm{O}_{4}$ 는 실험시편으로 사용한 AZ31 마그네슘 합금판재를 연결한 알루미늄(Al) 와이어가 일부 용해, 산화피막층을 형성할 때 반응한 것으로 보인다.

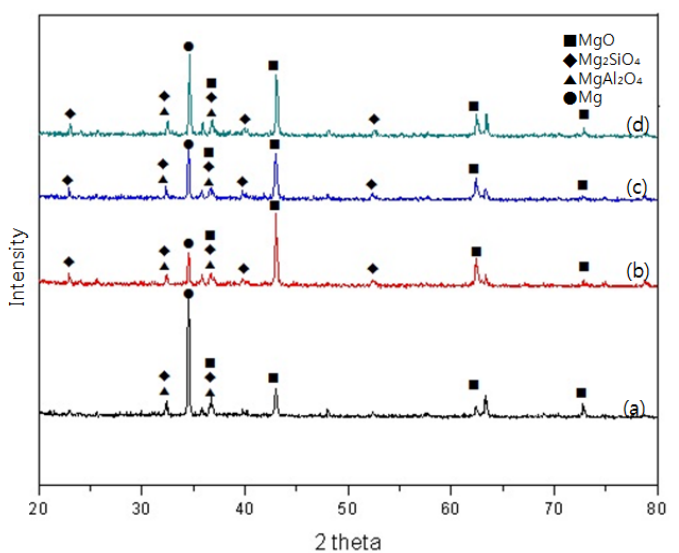

[그림 6] 알카리전해액(a:5min, b:15min)과 질산염첨가전 해액(c:15min),아질산염첨가 전해액(d:15min)으 로 제조한 산화피막층의 $\mathrm{XRD}$ 패턴

[Fig. 6] XRD patterns of AZ31 Mg alloy after MAO treated in $\mathrm{KOH}(3 \mathrm{~g} / \mathrm{L})+\mathrm{KF}(2 \mathrm{~g} / \mathrm{L})+\mathrm{Na}_{2} \mathrm{SiO}_{3}(5 \mathrm{~g} / \mathrm{L})$ electrolytes at (a) $5 \mathrm{~min}$, (b) $15 \mathrm{~min}$ and $\mathrm{NaNO}_{3}(0.5 \mathrm{~g} / \mathrm{L})$ contained electrolytes at (c) $15 \mathrm{~min}$ and $\mathrm{NaNO}_{2}(0.5 \mathrm{~g} / \mathrm{L})$ contained electrolytes at (d) $15 \mathrm{~min}$

$\mathrm{MAO}$ 반응 중에 일어나는 다양한 현상 즉, 전기분해, 시료 용해, 플라즈마 방전, $\operatorname{arc}$ 발생, 가스발생 등에 의해 
양극시편에 $\mathrm{Mg}$ 산화물이 생성하게 되는 것이다. 주요 $\mathrm{Mg}$ 산화물의 형성기구는 다음과 같다.[4]

$$
\begin{aligned}
& \mathrm{Mg} \rightarrow \mathrm{Mg}^{2+}+2 \mathrm{e}^{-} \\
& \mathrm{Mg}^{2+}+2 \mathrm{e}^{-}+\mathrm{H}_{2} \mathrm{O} \rightarrow \mathrm{MgO}+\mathrm{H}_{2}(\uparrow)
\end{aligned}
$$

$\mathrm{SiO}_{2}$ 는 $\mathrm{MAO}$ 반응 시에 전극표면에서 발생하는 $\operatorname{arc}$ 열에 의해 형성되는 것으로 보고되어 있으며 ${ }^{[10]} \mathrm{Mg}_{2} \mathrm{SiO}_{4}$ 는 $\mathrm{SiO}_{2}$ 와 $\mathrm{MgO}$ 가 반응하여 양극 표면에 나타나게 된 다.[11]

$$
\mathrm{SiO}_{2}+2 \mathrm{MgO} \rightarrow \mathrm{Mg}_{2} \mathrm{SiO}_{4}
$$

질산염이 첨가된 전해액에서 $\mathrm{MgO}$ 와 $\mathrm{Mg}_{2} \mathrm{SiO}_{4} \quad \mathrm{XRD}$ 분석결과 다소 높은 Intensity를 가지며 이는 경도값에 영 향을 미친것으로 판단된다.

그림7은 알카리 전해액중에 $400 \mathrm{~V}(100 \mathrm{~Hz}), 4 \mathrm{~A} / \mathrm{cm}^{2}$ 전 압을 인가하여 5 분 동안 반응한 시료(a)와 $\mathrm{NaNO}_{3}(0.5 \mathrm{~g} / \mathrm{L})$ 첨가된 전해액에 5 분 동안 반응한 시료(b), $\mathrm{NaNO}_{2}(0.5 \mathrm{~g} / \mathrm{L})$ 첨가된 전해액은 5 분 동안 반응한 시료(c)의 염수분무 시 험 결과로 모든 시료에서 부식특성이 양호한 것을 확인 할 수 있었다.

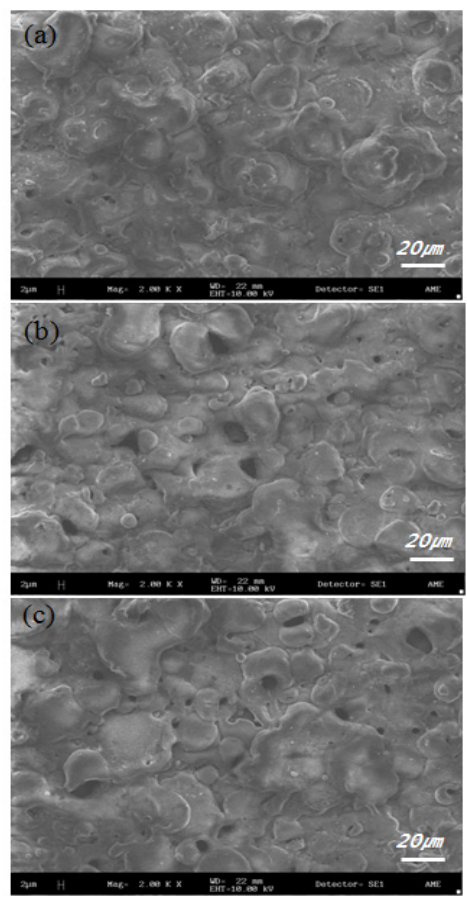

[그림 7] MAO처리한 AZ31합금의 염수분무시험후의 표면 형상

[Fig. 7] Surface morphologies of AZ31 Mg alloy on salt spray test $\left(5 \% \mathrm{NaCl}, 168\right.$ hour, T.C.: $\left.35^{\circ} \mathrm{C}\right)$

\section{4. 결 론}

알카리 및 질산염을 첨가한 전해액을 이용하여 AZ31 마그네슘 합금의 산화피막 형성에 대한 거동 및 기계적 특성, 내식성 테스트를 한 결과 다음과 같은 결론을 얻었다.

질산염 $\mathrm{NaNO}_{3}(0.5 \mathrm{~g} / \mathrm{L})$ 와 $\mathrm{NaNO}_{2}(0.5 \mathrm{~g} / \mathrm{L})$ 가 첨가된 전 해액에서 기존 알카리 전해액에 비해 산화피막층의 두께 는 증가하지 않았지만, 활발한 반응과 함께 알카리 전해 액보다 더 큰 경도값을 나타내고 있으며, 이는 XRD실험 을 통해 산화피막층에 생성된 $\mathrm{MgO}, \mathrm{Mg}_{2} \mathrm{SiO}_{4}$ 로 확인할 수 있었다. 알카리 및 질산염첨가 전해액 모두에서 산화 피막층 표면에 크랙 및 기공이 관찰되었지만 염수분무시 험 결과 $400 \mathrm{~V}(100 \mathrm{~Hz}), 4 \mathrm{~A} / \mathrm{cm}^{2}$ 전압을 인가하여 5 분 동안 반응하여 제조한 $\mathrm{MAO}$ 시료에서도 부식 없이 견고한 산 화피막층을 유지하고 있었다.

\section{References}

[1] M.A. Gonzalez-nunez, C.A.Nunez-lopez, P.Skeldon, G.E.Thompson, H.Karimzadeh, P.Lyon, T.E.Wilks, Corros. Sci. 37, 1763-1772, 1995.

[2] M.Shahid, et all J.Mater.Sci. 32, 3775-3781, 1997

[3] A.A.Voevodin, et al., Characterization of wear protective Al-Si-O coatings formed on Al-based alloys by micro arc discharge treatment, Surf. Coat. Techn ol. 516, 86-87, 1996.

[4] A.L.Yerokhin, X.Nie, A.Leyland, A.Matthews and S.J.Dowey, Plasma electrolysis for surface engineering, Surf.Coat. Technol. 122, 73-93, 1999.

[5] http://www.keronite.co.uk/

[6] A.L Yerokhin, A.A.Voevodin, V.V. Lyubimov, J. Zibinsk, M. Donley, Plasma electrolytic fabrication of oxide ceramic sufaced layers for tribotechnical purposes on Al alloys, Surf. Coat. Techno, 110, 140-146, 1998.

[7] Kai Wang, S.S. Byeon, B.H. Koo, "Nitrogen inducing effect on preparation of $\mathrm{AlON}-\mathrm{Al}_{2} \mathrm{O}_{3}$ coatings on Al6061 alloy by EPP", Surf.Coat.Technol. 205, S11-S14, 2010.

[8] J.A.Curran and T.W.Clyne, Prosisty in plasma electrolytic oxide coatings, Acta Materialia 54, 1985-1993, 2006.

[9] C.Blawert, W.Dietzel, E.Ghali, G Song, Anodizing treatments for magnesium alloys and their effect on corrosion resistance in various environments. Adv. Eng. Mater., 8, 511, 2006.

[10] V.Brass, S.Xia, R.Yue, G.Richard, Rateick Jr., 
"Characterization of oxide films formed on mg-based WE43 alloy using AC/DC anodization in silicate solutions, J. Electrochem. Soc., 151, B1-10, 2004.

[11] H.F.Guo, M.Z.An, H.B.Huo, S.Xu, L.J.Wu, Microstructure characteristic of ceramic coatings fabricated on $\mathrm{mg}$ alloys by MAO in alkaline silicate solutions, Appl. Surf. Sci., 252, 7911-7916, 2006.

[12] L.Chai, X.Yu, Z.Yang, Y.Wang, M.Okido, Corrosion Science, 50, 3274, 2008.

[13] S.S.Byeon, K.Wang, Y.G.Jung, B.H.Koo, Surf. Coat. Technol. 204, 3196-3199, 2010.

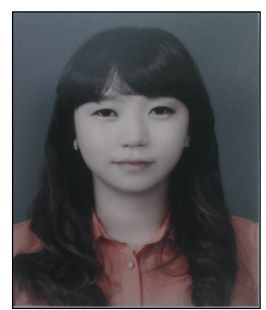

- 2009년 3월 현재 : 공주대학교 신소재공학부 4 학년 재학

<관심분야>

경량소재, 재료평가

\section{조 영 희(Young-Hee Cho)}

[정회원]

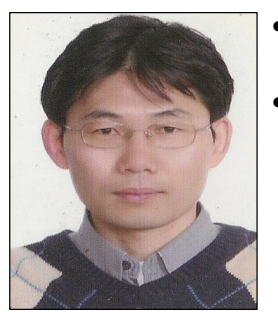

- 2011년 2월 : 공주대학교 대학원 재료공학과 박사과정

- 2010년 3월 현재 : 하나에이 엠티(주) 기술연구소 근무

<관심분야>

경량소재, 분말야금

\section{장 경 수(Kyong-Soo Jang)}

[준회원]

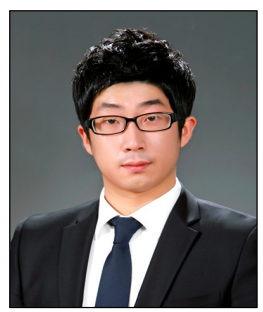

- 2008년 3월 현재 : 공주대학교 신소재공학부 4학년 재학

<관심 분야>

경량소재, 분말야금

[준회원]

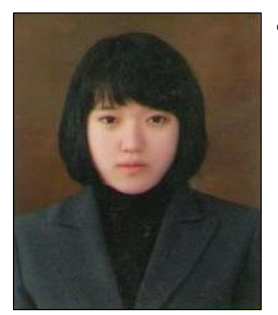

- 2009년 3월 현재 : 공주대학교 신소재공학부 4학년 재학

<관심분야>

경량소재, $\mathrm{MAO}$

\section{이 태 행(Tae-Haeng Lee)}

[정회원]

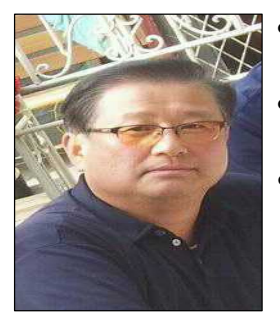

- 1990년 8월 : 충남대학교 금속공 학과(공학박사)

- 1991년 6월 1993년 2월 : 공 업진흥청(현 중기청) 근무

- 1993년 3월 현재 : 공주대학 교 신소재공학부 교수

<관심분야>

비철금속, 분말야금, 경량소재 